\title{
Hematocrit levels and thrombotic events in patients with polycythemia vera: an analysis of Veterans Health Administration data
}

\author{
Shreekant Parasuraman ${ }^{1} \cdot$ Jingbo $\mathrm{Yu}^{1} \cdot$ Dilan Paranagama $^{1}$ (I) $\cdot$ Sulena Shrestha ${ }^{2} \cdot$ Li Wang $^{2} \cdot$ Onur Baser $^{2,3,4}$. \\ Robyn Scherber ${ }^{5}$
}

Received: 4 June 2019 / Accepted: 29 August 2019/Published online: 24 September 2019

(C) The Author(s) 2019

\begin{abstract}
Patients with polycythemia vera (PV) have a high incidence of thrombotic events (TEs), contributing to a greater mortality risk than the general population. The relationship between hematocrit (HCT) levels and TE occurrence among patients with PV from the Veterans Health Administration (VHA) was evaluated to replicate findings of the CYTO-PV trial with a real-world patient population. This retrospective study used VHA medical record and claims data from the first claim with a PV diagnosis (index) until death, disenrollment, or end of study, collected between October 1, 2005, and September 30, 2012. Patients were aged $\geq 18$ years at index, had $\geq 2$ claims for PV (ICD-9-CM code, 238.4) $\geq 30$ days apart during the identification period, continuous health plan enrollment from 12 months pre-index until end of study, and $\geq 3$ HCT measurements per year during follow-up. This analysis focused on patients with no pre-index TE, and with all HCT values either $<45 \%$ or $\geq 45 \%$ during the follow-up period. The difference in TE risk between HCT groups was assessed using unadjusted Cox regression models based on time to first TE. Patients $(N=213)$ were mean (SD) age $68.9(11.5)$ years, $98.6 \%$ male, and $61.5 \%$ white. TE rates for patients with HCT values $<45 \%$ versus $\geq 45 \%$ were $40.3 \%$ and $54.2 \%$, respectively. Among patients with $\geq 1$ HCT before TE, TE risk hazard ratio was $1.61(95 \% \mathrm{CI}, 1.03-2.51 ; P=0.036)$. This analysis of the VHA population further supports effective monitoring and control of HCT levels $<45 \%$ to reduce TE risk in patients with PV.
\end{abstract}

Keywords Hematocrit $\cdot$ Polycythemia vera $\cdot$ Retrospective study $\cdot$ Thrombosis $\cdot$ Thromboembolism $\cdot$ Thrombotic event

\section{Introduction}

Patients with polycythemia vera (PV) are at risk for arterial and venous thrombotic events (TEs). In a large international,

Shreekant Parasuraman

sparasuraman@incyte.com

1 Incyte Corporation, 1801 Augustine Cut-Off, Wilmington, DE 19803, USA

2 STATinMED Research, 5360 Legacy Dr Ste 120, Plano, TX 75024, USA

3 Internal Medicine - Rheumatology, University of Michigan, 3918 TC, Ann Arbor, MI 48109, USA

4 Department of Economics, MEF University, Ayazağa St. No.4 34396, Maslak, Sarıyer, Istanbul, Turkey

5 UT Health San Antonio MD Anderson Cancer Center, 7979 Wurzbach Rd, San Antonio, TX 78229, USA retrospective study, $12 \%$ of patients with PV had an arterial TE and $9 \%$ had a venous TE over a median follow-up of 7 years [1]. Across several studies, rates of arterial and venous TEs in patients with PV ranged from 0.7 to 2.1 and 0.5 to 2.0 per 100 person-years, respectively [2-5]. Thrombotic complications have been reported as a leading cause of death for patients with PV, and prior thrombosis, particularly venous, has been identified as prognostic for overall survival [1]. Taken together, TEs may contribute to the lower survival rate observed in patients with PV compared with the general population [6].

The National Comprehensive Care Network Clinical Practice Guidelines in Oncology (NCCN Guidelines $®)$ emphasizes prevention of thrombosis occurrence and recurrence as a primary treatment goal for PV, along with controlling disease-related symptoms [7]. This recommendation is supported by the findings of the European Collaboration on Low-Dose Aspirin in Polycythemia Vera (ECLAP) study, which observed a significant reduction in the risk of TE and 
death from cardiovascular causes in patients treated with aspirin [8]. In addition, hematocrit (HCT) control is associated with reduced thrombotic risk in patients with $\mathrm{PV}$, as observed in the Italian Cytoreductive Therapy in Polycythemia Vera (CYTO-PV) trial [9]. In brief, the CYTO-PV trial randomized participants 1:1 to 2 groups: one with an HCT target of $<45 \%$ (low-HCT group) and the other with an HCT target of 45 to $50 \%$ (high-HCT group). Patients in the low-HCT group had a significantly lower rate of cardiovascular death and major thrombosis than those in the high-HCT group [9].

The study described here reports the results of a retrospective analysis of Veterans Health Administration (VHA) claims data. The VHA is the largest integrated healthcare system in the USA and provides real-world data on a robust patient population. The aim of this study was to investigate the relationship between HCT levels and TE occurrence among patients with PV and is the first to replicate the CYTO-PV findings in a real-world setting.

\section{Methods}

\section{Database characteristics}

The VHA consists of 150 medical centers and nearly 1400 community-based outpatient clinics, veteran's centers, and domiciliary. In 2014, 9.11 million patients were enrolled in the VHA healthcare system; enrollees were primarily non-Hispanic white $(82.3 \%)$ men $(91.0 \%)$ under 65 years old (54.8\%) [10]. VHA records provide longitudinal data, capturing the full episode of care of the VHA population. The dataset analyzed here included de-identified patient-level data from 21 Veterans Integrated Service Networks linking inpatient, outpatient, pharmacy, laboratory, enrollment, and vital sign databases.

\section{Study design}

This retrospective observational claims study analyzed VHA Medical SAS® Dataset data cataloged between October 1, 2005, and September 30, 2012 (Fig. 1). Patients were monitored from the index date (defined as the date of each patient's first claim with a PV diagnosis during the identification period [October 1, 2006, to September 30, 2007]) until death, disenrollment, or end of the follow-up period (September 30, 2012; Fig. 1).

\section{Patients}

Patients included in the analysis had $\geq 2$ claims for PV (International Classification of Diseases, Ninth Revision, Clinical Modification [ICD-9-CM] code: 238.4 ) $\geq 30$ days apart during the identification period, were $\geq 18$ years old on the index date, were continuously enrolled in a health plan with medical and pharmacy benefits from 12 months preindex until the end of the study period, and had $\geq 3$ HCT and $\geq 3$ white blood cell (WBC) measurements per year during the follow-up period (WBC data analyzed and reported in a separate study). Patients with a pre-index TE were excluded from the primary analysis. This analysis included patients whose observed HCT levels were consistently within strict boundaries, always either $<45 \%$ or $\geq 45 \%$ during the follow-up period.

\section{Definition of TE}

Patients who had a TE were defined as those with a diagnosis in medical claims during the follow-up period for at least one of the following conditions: ischemic stroke, acute myocardial infarction, deep vein thrombosis, pulmonary embolism, transient ischemic attack, peripheral arterial thrombosis, and superficial thrombophlebitis. More than one type of TE could be recorded in a single visit; therefore, the first event could include more than one type of TE per patient.

\section{Statistical analyses}

Patient demographics and disease characteristics, baseline comorbidities, and TEs were described using descriptive statistics. Comorbid conditions were measured using the DeyoCharlson Comorbidity Index, which assigns a weighted score ranging from 1 to 6 according to disease severity for 19 conditions [11], and the Chronic Disease Score, an aggregate comorbidity measure based on medication use (derived from pharmacy claims data) [12]. Any differences between the two HCT groups in the risk of TE were assessed using unadjusted Cox regression models based on time to first TE. For patients with a TE during follow-up, only those with $\geq 1$ HCT measurement before the event were included in the Cox regression models. Time to first TE was defined as the period between index date and first claim associated with a TE diagnosis; patients were censored at the time of death, disenrollment, or end of the follow-up period. The primary analysis included patients without a history of TE before the index date; a sensitivity analysis including patients with a history of TE prior to the index period was also performed.

\section{Results}

\section{Patients}

There were 3943 patients who had $\geq 2$ medical claims for PV during the identification period. In total, $1876 \mathrm{had} \geq 3 \mathrm{HCT}$ and $\geq 3$ WBC measurements per year, of whom 342 had consistent HCT status throughout follow-up. Of these patients, 213 did not experience a TE during the pre-index period 


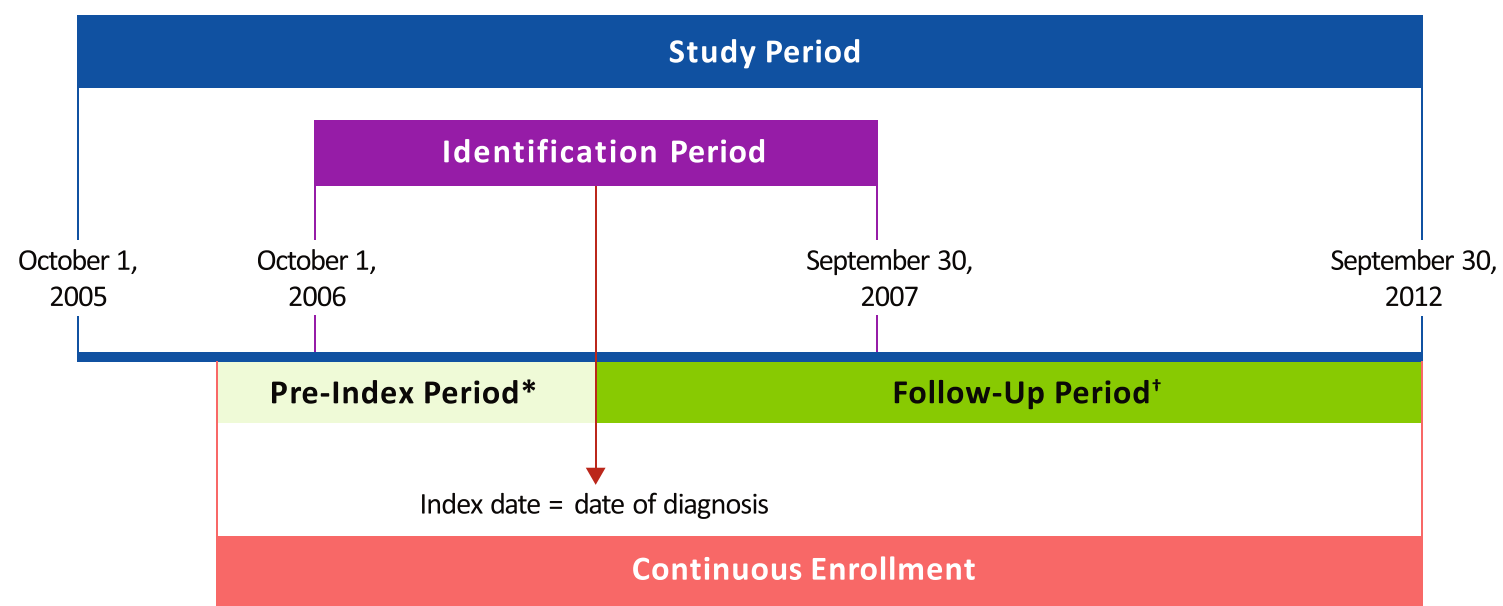

Fig. 1 Study design schematic. $* \geq 12$ months. ${ }^{\dagger}$ Patients were monitored from index date until the date of the earliest event: death, disenrollment, or end of the study period

( $\mathrm{HCT}<45 \%, n=154$; HCT $\geq 45 \%, n=59$; Fig. 2) and were included in the primary analysis.

Among the 213 patients included in the analysis, most were male $(98.6 \%)$ and white $(61.5 \%)$, with a mean (SD) age of 68.9 (11.5) years (Table 1). The mean (SD) Deyo-modified Charlson Comorbidity Index score and Chronic Disease Score were 1.46 (1.56) and 7.34 (4.37), respectively, indicating a notable pre-index comorbidity burden. The most common comorbidities were hypertension $(72.8 \%)$, dyslipidemia $(37.6 \%)$, chronic obstructive pulmonary disease $(24.9 \%)$, and diabetes (17.4\%). Use of smoking cessation therapy (used as a surrogate measure of smoking rate) was present for $23.9 \%$ of the patients.

\section{TEs during follow-up}

Among qualifying patients, 44.1\% (94/213) experienced a TE during follow-up (mean follow-up, 2.3 years; rate per 100 person-years, 18.9; Fig. 3). The 3 most common types of TE recorded as the first event during follow-up were ischemic stroke $(21.6 \%, 46 / 213)$, deep vein thrombosis $(12.2 \%, 26 / 213)$, and transient ischemic attack $(9.4 \%, 20 / 213$; Table 2$)$. Patients with HCT levels $<45 \%$ ( $n=154$; median follow-up, 2.48 years) compared with those with levels $\geq 45 \%$ ( $n=59$; median follow-up, 1.97 years) had a lower risk of TE (40.3\% vs $54.2 \%$, respectively; Fig. 3). A statistically significant increased risk of TE was observed among patients with HCT levels $\geq 45 \%$ compared with those with HCT levels $<45 \%$ (hazard ratio [HR] calculation including 208 patients with $\geq 1 \mathrm{HCT}$ value before first TE, $1.61 ; 95 \% \mathrm{CI}, 1.03-2.51 ; P=0.036)$.

Mean body mass index (BMI) at the index date was lower among patients with a consistent HCT $<45 \%$ who did not experience a TE compared with those who did experience a TE (26.2 vs $29.4 \mathrm{~kg} / \mathrm{m}^{2}$, respectively). Patients with a consistent $\mathrm{HCT} \geq 45 \%$ had nearly identical mean index date BMI, regardless of TE during follow-up (31.2 vs $\left.31.3 \mathrm{~kg} / \mathrm{m}^{2}\right)$.
The sensitivity analysis conducted including patients with and without TE prior to index $(n=342)$ had similar results to the primary analysis $(55.6 \%$ vs $76.9 \%$ between the $<45 \%$ and $\geq 45 \%$ groups, respectively; HR calculation including 322 patients with $\geq 1$ HCT value before first TE, 1.95 ; 95\% CI, 1.462.61; $P<0.0001)$.

\section{Discussion}

This retrospective analysis of VHA claims data evaluated the relationship between HCT levels and TE occurrence among patients with PV in a real-world setting. Results from this analysis are consistent with those reported in CYTO-PV [9], which identified increased risk of TE in patients with HCT $\geq 45 \%$ versus $<45 \%$ and a risk of death from cardiovascular causes or major thrombosis that was 4 times greater in the group with high HCT. In the present study, patients with HCT levels that were consistently $\geq 45 \%$ had a $70 \%$ increased risk of TE compared with those with HCT levels that were consistently $<45 \%$.

Patients with consistently high HCT ( $\geq 45 \%$ ) have suboptimal control of disease and may require changes to the management of their disease, such as initiation of effective cytoreductive therapy, to improve clinical outcomes. A separate analysis of cytoreductive treatment patterns in predominantly $(73.8 \%)$ high-risk patients with PV from the VHA patient population revealed that only $23.2 \%$ of patients had a record of any pharmacologic cytoreductive treatment [13], in contrast to NCCN Guidelines® [7]. Among patients with HCT levels $<45 \%$, effective monitoring and maintenance may lead to a reduction in the risk of TE by identifying changes in HCT control and cardiovascular risk factors before the occurrence of a TE. The association between the occurrence of TE and the effectiveness of treatments used to maintain 


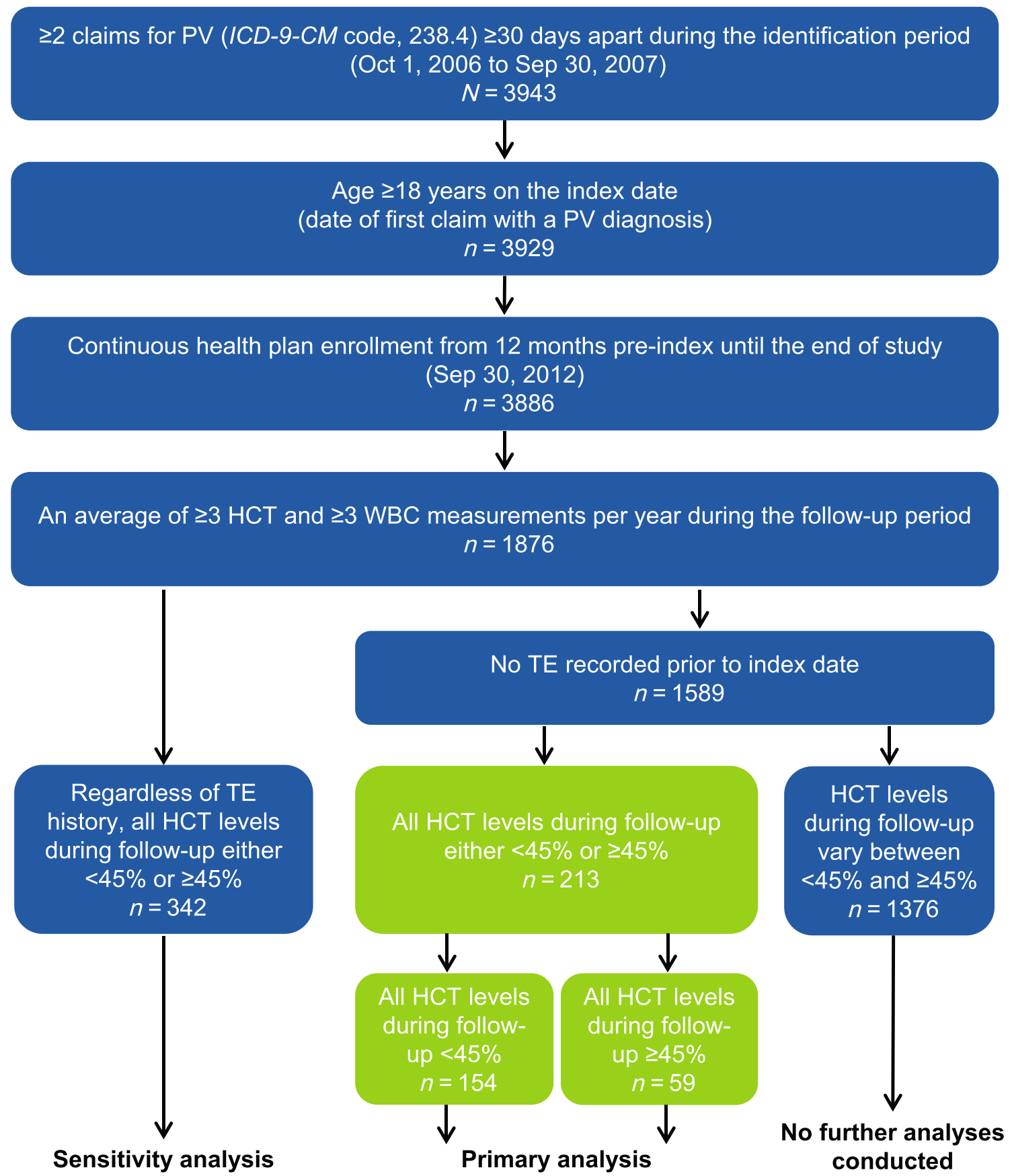

Fig. 2 Patient selection and attrition. HCT, hematocrit; ICD-9-CM, International Classification of Diseases, Ninth Revision, Clinical Modification; PV, polycythemia vera; TE, thrombotic event; WBC, white blood cell

HCT values below a 45\% threshold was outside the scope of this study and not assessed.

When interpreting the results of the current study, it is important to note that the VHA patient population is a unique population with key differences from the general patient population. The VHA patient population analyzed in this study was predominantly male (98.6\%). Overall, rates of cardiovascular risk factors and comorbidities are higher in the VHA patient population versus the general population [14]. Baseline comorbidity scores indicated a significant comorbid disease burden, even compared with patients with PV in the general US population (Charlson Comorbidity Index score, 1.29 vs 0.8 ) [5]. Furthermore, several of the most common baseline comorbid conditions (i.e., hypertension, dyslipidemia, smoking [based on use of smoking cessation therapy], and diabetes) are among the risk factors typically associated with cardiovascular disease [15]. Although not recorded in this study, psychological comorbidities (e.g., posttraumatic stress disorder) [16] and psychosocial issues (e.g., homelessness) [17] have also been documented in the VHA patient 
Table 1 Patient demographics and clinical characteristics at index date

\begin{tabular}{|c|c|c|c|}
\hline \multirow[t]{2}{*}{ Characteristic } & \multicolumn{3}{|c|}{ No pre-index TE and consistent HCT } \\
\hline & $\begin{array}{l}\text { Total } \\
(n=213)\end{array}$ & $\mathrm{HCT}<45 \%(n=154)$ & $\mathrm{HCT} \geq 45 \%(n=59)$ \\
\hline Mean (SD) age, years & $68.9(11.5)$ & $71.8(10.7)$ & $61.2(10.0)$ \\
\hline Male, $n(\%)$ & $210(98.6)$ & $151(98.1)$ & $59(100)$ \\
\hline \multicolumn{4}{|l|}{ Race/ethnicity, $n(\%)$} \\
\hline White & $131(61.5)$ & $97(63.0)$ & $34(57.6)$ \\
\hline Black & $19(8.9)$ & $13(8.4)$ & $6(10.2)$ \\
\hline Hispanic & $10(4.7)$ & $8(5.2)$ & $2(3.4)$ \\
\hline Other & $53(24.9)$ & $36(23.4)$ & $17(28.8)$ \\
\hline Mean (SD) BMI, $\mathrm{kg} / \mathrm{m}^{2}$ & $28.5(12.3)$ & $27.5(13.6)$ & $31.3(6.9)$ \\
\hline \multicolumn{4}{|l|}{ Comorbidities } \\
\hline Mean (SD) Deyo-modified CCI score & $1.46(1.56)$ & $1.64(1.66)$ & $0.97(1.13)$ \\
\hline Mean (SD) CDS & $7.34(4.37)$ & $7.65(4.43)$ & $6.53(4.10)$ \\
\hline \multicolumn{4}{|l|}{$\begin{array}{l}\text { Common comorbidities and } \\
\text { health-related behaviors, } n(\%)\end{array}$} \\
\hline Hypertension & $155(72.8)$ & $115(74.7)$ & $40(67.8)$ \\
\hline Dyslipidemia & $80(37.6)$ & $52(33.8)$ & $28(47.5)$ \\
\hline COPD & $53(24.9)$ & $35(22.7)$ & $18(30.5)$ \\
\hline Diabetes & $37(17.4)$ & $29(18.8)$ & $8(13.6)$ \\
\hline Cardiovascular event & $33(15.5)$ & $24(15.6)$ & $9(15.3)$ \\
\hline Bleeding & $23(10.8)$ & $18(11.7)$ & $5(8.5)$ \\
\hline Asthma & $6(2.8)$ & $5(3.2)$ & $1(1.7)$ \\
\hline Smoking $^{\mathrm{a}}$ & $51(23.9)$ & $28(18.2)$ & $23(39.0)$ \\
\hline
\end{tabular}

$B M I$, body mass index; $C C I$, Charlson Comorbidity Index; $C D S$, Chronic Disease Score; $C O P D$, chronic obstructive pulmonary disease; $H C T$, hematocrit; $T E$, thrombotic event

${ }^{a}$ Based on use of smoking cessation therapy in claims population and could pose challenges in properly managing TEs. Taken together, these attributes of the VHA patient population may have contributed to the high TE rate observed in this analysis, with more than a quarter of those with no preindex TE experiencing a TE during follow-up (rate of 18.9 per 100 person-years). In comparison, a recent observational

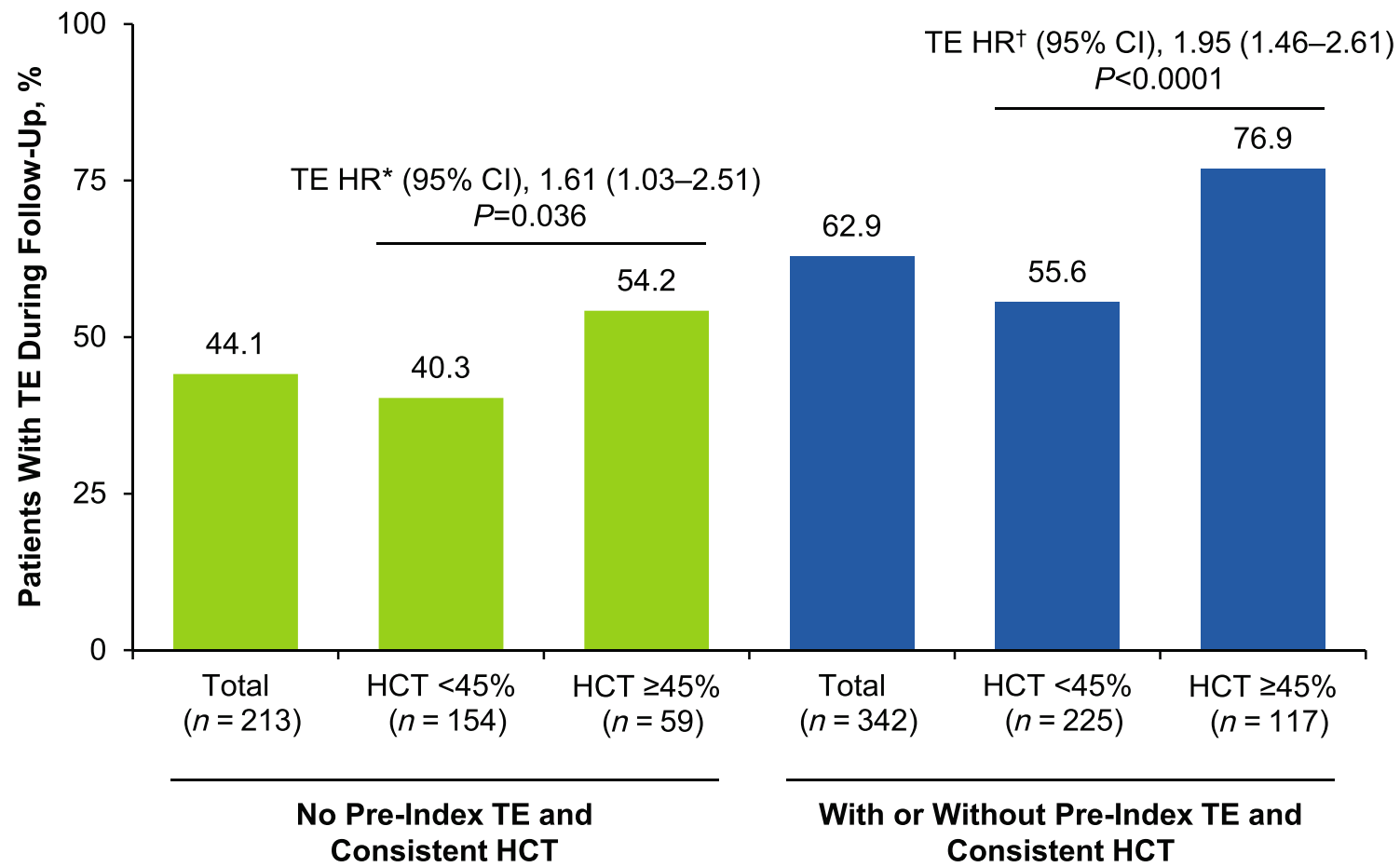

Fig. 3 TE during follow-up. HCT, hematocrit; $\mathrm{HR}$, hazard ratio; TE, thrombotic event. *HR calculation based on patients with $\geq 1 \mathrm{HCT}$ value before first $\mathrm{TE}(n=208) .{ }^{\dagger} \mathrm{HR}$ calculation based on patients with $\geq 1 \mathrm{HCT}$ value before first TE $(n=322)$ 
Table 2 Rates and types of TE during follow-up

\begin{tabular}{|c|c|c|c|c|c|c|}
\hline & \multicolumn{6}{|c|}{ No pre-index TE and consistent HCT } \\
\hline & \multicolumn{2}{|l|}{ Total $(n=213)$} & \multicolumn{2}{|c|}{$\mathrm{HCT}<45 \%(n=154)$} & \multicolumn{2}{|c|}{$\mathrm{HCT} \geq 45 \%(n=59)$} \\
\hline & Patients, $n(\%)$ & $\begin{array}{l}\text { Incidence rate } \\
\text { per } 100 \text { person-years }\end{array}$ & Patients, $n(\%)$ & $\begin{array}{l}\text { Incidence rate } \\
\text { per } 100 \text { person-years }\end{array}$ & Patients, $n(\%)$ & $\begin{array}{l}\text { Incidence rate } \\
\text { per } 100 \text { person-years }\end{array}$ \\
\hline TE & $94(44.1)$ & 18.9 & $62(40.3)$ & 16.2 & $32(54.2)$ & 27.5 \\
\hline Ischemic stroke & $46(21.6)$ & 9.2 & $29(18.8)$ & 7.6 & $17(28.8)$ & 14.6 \\
\hline Deep vein thrombosis & $26(12.2)$ & 5.2 & $21(13.6)$ & 5.5 & $5(8.5)$ & 4.3 \\
\hline Transient ischemic attack & $20(9.4)$ & 4.0 & $10(6.5)$ & 2.6 & $10(17.0)$ & 8.6 \\
\hline Acute myocardial infarction & $15(7.0)$ & 3.0 & $12(7.8)$ & 3.1 & $3(5.1)$ & 2.6 \\
\hline Pulmonary embolism & $15(7.0)$ & 3.0 & $11(7.1)$ & 2.9 & $4(6.8)$ & 3.4 \\
\hline Peripheral arterial thrombosis & $5(2.4)$ & 1.0 & $1(0.7)$ & 0.3 & $4(6.8)$ & 3.4 \\
\hline Superficial thrombophlebitis & $3(1.4)$ & 0.6 & $2(1.3)$ & 0.5 & $1(1.7)$ & 0.9 \\
\hline
\end{tabular}

$H C T$, hematocrit; $T E$, thrombotic event

study of patients with PV in the general US population $(N=$ 8124) reported a rate of 1.43 per 100 person-years [5].

Body mass index is also an important contributor to adverse cardiovascular outcomes and risk [18]. Among patients with low HCT $(<45 \%)$, those who experienced a TE during follow-up had higher index BMI. BMI may be more indicative of TE risk than comorbidities, as scores for both Charlson Comorbidity Index and Chronic Disease Score were higher for the low-HCT $(<45 \%)$ group than the high-HCT ( $\geq 45 \%)$ group.

A key strength of this analysis is that the methodology used real-world data from patients in 2 groups based on consistent HCT levels $<45 \%$ or $\geq 45 \%$, similar to the groups evaluated in the CYTO-PV study. Limitations of this study are attributable to its retrospective design and the accuracy of the VHA medical database. The sample sizes for the consistent HCT cohorts were small; however, they were similar to the population sizes recorded in the CYTO-PV study $(<45 \%$, $n=182 ; \geq 45 \%, n=183$ ) [9]. The real-world nature of the study data means that the characteristics of the two cohorts may differ, and could not be controlled for without making the model unstable. The outcome variables (e.g., TE) and other clinical conditions (e.g., PV) were identified using $I C D-9-C M$ codes, which are subject to potential miscoding. This was also applicable to smoking rates, which were likely underestimated, as they were identified using ICD-9-CM codes for management associated with smoking cessation. Moreover, potential misclassification of HCT values could have led to information bias. Platelet counts as well as overthe-counter aspirin use were not available in the VHA database. Lastly, it is important to note that because of the large difference in sociodemographic characteristics, health status, resource use, and costs between the VHA population and the general US population, the results of this study may not be generalizable to the US population.

\section{Conclusion}

Among VHA patients with PV, those with HCT levels consistently $\geq 45 \%$ had a significantly higher risk of TE than patients with HCT levels consistently $<45 \%$. The results of this retrospective analysis of a real-world population are in agreement with findings from the CYTO-PV study and further support effective monitoring and management of HCT levels $<45 \%$ to reduce the risk of TE in patients with PV.

Acknowledgments Writing assistance was provided by Tania Iqbal, $\mathrm{PhD}$, and Lauriaselle Afanador, $\mathrm{PhD}$ (Complete Healthcare Communications, LLC [North Wales, PA], a CHC Group company).

Funding information This work was funded by Incyte Corporation (Wilmington, DE).

Data availability The dataset supporting the conclusions in this article is available from the US Veterans Health Administration. However, restrictions apply to the availability of these data, which were used under license for the current study, and so are not publicly available.

\section{Compliance with ethical standards}

Conflict of interest SP, JY, and DP are employees and stockholders of Incyte Corporation. SS, LW, and OB are employees and stockholders of STATinMED Research, which is a paid consultant of Incyte Corporation. RS has received honoraria from Novartis and Gilead.

Ethical approval Not applicable: This retrospective database analysis used de-identified data. As such, Institutional Review Board (IRB) approval to conduct this analysis was not required. This analysis complies with the Health Insurance Portability and Accountability Act of 1996 (HIPAA) and its implementing regulations of Title 45 Code of Federal Regulations Parts 160 and 164 ("HIPAA Privacy and Security Rules"). 
Open Access This article is distributed under the terms of the Creative Commons Attribution 4.0 International License (http:// creativecommons.org/licenses/by/4.0/), which permits unrestricted use, distribution, and reproduction in any medium, provided you give appropriate credit to the original author(s) and the source, provide a link to the Creative Commons license, and indicate if changes were made.

\section{References}

1. Tefferi A, Rumi E, Finazzi G, Gisslinger H, Vannucchi AM, Rodeghiero F, Randi ML, Vaidya R, Cazzola M, Rambaldi A, Gisslinger B, Pieri L, Ruggeri M, Bertozzi I, Sulai NH, Casetti I, Carobbio A, Jeryczynski G, Larson DR, Müllauer L, Pardanani A, Thiele J, Passamonti F, Barbui T (2013) Survival and prognosis among 1545 patients with contemporary polycythemia vera: an international study. Leukemia 27(9):1874-1881. https://doi.org/ 10.1038/leu.2013.163

2. Barbui T, Carobbio A, Rumi E, Finazzi G, Gisslinger H, Rodeghiero F, Randi ML, Rambaldi A, Gisslinger B, Pieri L, Bertozzi I, Casetti I, Pardanani A, Passamonti F, Vannucchi AM, Tefferi A (2014) In contemporary patients with polycythemia vera, rates of thrombosis and risk factors delineate a new clinical epidemiology. Blood 124(19):3021-3023. https://doi.org/10.1182/ blood-2014-07-591610

3. Marchioli R, Finazzi G, Landolfi R, Kutti J, Gisslinger H, Patrono C, Marilus R, Villegas A, Tognoni G, Barbui T (2005) Vascular and neoplastic risk in a large cohort of patients with polycythemia vera. J Clin Oncol 23(10):2224-2232. https://doi.org/10.1200/JCO. 2005.07.062

4. Vannucchi AM, Antonioli E, Guglielmelli P, Rambaldi A, Barosi G, Marchioli R, Marfisi RM, Finazzi G, Guerini V, Fabris F, Randi ML, De Stefano V, Caberlon S, Tafuri A, Ruggeri M, Specchia G, Liso V, Rossi E, Pogliani E, Gugliotta L, Bosi A, Barbui T (2007) Clinical profile of homozygous JAK2 $617 \mathrm{~V}>\mathrm{F}$ mutation in patients with polycythemia vera or essential thrombocythemia. Blood 110(3):840-846

5. Goyal RK, Davis KL, Cote I, Mounedji N, Kaye JA (2014) Increased incidence of thromboembolic event rates in patients diagnosed with polycythemia vera: results from an observational cohort study. Blood (ASH Annual Meeting Abstracts):abstract 4840

6. Hultcrantz M, Kristinsson SY, Andersson TM, Landgren O, Eloranta S, Derolf AR, Dickman PW, Björkholm M (2012) Patterns of survival among patients with myeloproliferative neoplasms diagnosed in Sweden from 1973 to 2008: a populationbased study. J Clin Oncol 30(24):2995-3001. https://doi.org/10. 1200/JCO.2012.42.1925

7. National Comprehensive Care Network (2017) NCCN Clinical Practice Guidelines in Oncology (NCCN Guidelines $\left.{ }^{\circledR}\right)$ Version 2.2018. https://www.nccn.org/professionals/physician_gls/pdf/ mpn.pdf. Accessed March 82018

8. Landolfi R, Marchioli R, Kutti J, Gisslinger H, Tognoni G, Patrono C, Barbui T, European Collaboration on Low-Dose Aspirin in Polycythemia Vera Investigators (2004) Efficacy and safety of low-dose aspirin in polycythemia vera. N Engl J Med 350(2): 114-124. https://doi.org/10.1056/NEJMoa035572

9. Marchioli R, Finazzi G, Specchia G, Cacciola R, Cavazzina R, Cilloni D, De Stefano V, Elli E, Iurlo A, Latagliata R, Lunghi F, Lunghi M, Marfisi RM, Musto P, Masciulli A, Musolino C, Cascavilla N, Quarta G, Randi ML, Rapezzi D, Ruggeri M, Rumi E, Scortechini AR, Santini S, Scarano M, Siragusa S, Spadea A, Tieghi A, Angelucci E, Visani G, Vannucchi AM, Barbui T, CYTOPV Collaborative Group (2013) Cardiovascular events and intensity of treatment in polycythemia vera. N Engl J Med 368(1):22-33. https://doi.org/10.1056/NEJMoa1208500

10. Department of Veterans Affairs, Office of the Actuary (2014) Veteran Population Projection Model (VetPop) 2014; Veterans Benefits Administration; Veterans Health Administration, Office of the Assistant Deputy Under Secretary for Health for Policy and Planning. https://www.va.gov/vetdata/veteran_population.asp. Accessed 8 Mar 2019

11. Charlson M, Szatrowski TP, Peterson J, Gold J (1994) Validation of a combined comorbidity index. J Clin Epidemiol 47(11):12451251

12. Von Korff M, Wagner EH, Saunders K (1992) A chronic disease score from automated pharmacy data. J Clin Epidemiol 45(2):197203

13. Parasuraman S, Yu J, Paranagama D, Shrestha S, Wang L, Baser O, Scherber R (2018) Cytoreductive treatment patterns among US veterans with polycythemia vera. BMC Cancer 18(1):528

14. Klein S (2011) The Veterans Health Administration: implementing patient-centered medical homes in the nation's largest integrated delivery system. Commonw Fund 1537(16):1-24

15. Goff DC Jr, Lloyd-Jones DM, Bennett G, Coady S, D'Agostino RB Sr, Gibbons R, Greenland P, Lackland DT, Levy D, O'Donnell CJ, Robinson JG, Schwartz JS, Shero ST, Smith SC Jr, Sorlie P, Stone NJ, Wilson PW, American College of Cardiology/American Heart Association Task Force on Practice Guidelines (2014) 2013 ACC/ AHA guideline on the assessment of cardiovascular risk: a report of the American College of Cardiology/American Heart Association Task Force on Practice Guidelines. J Am Coll Cardiol 63(25 Pt B): 2935-2959

16. Seal KH, Bertenthal D, Miner CR, Sen S, Marmar C (2007) Bringing the war back home: mental health disorders among 103,788 US veterans returning from Iraq and Afghanistan seen at Department of Veterans Affairs facilities. Arch Intern Med 167(5):476-482

17. Byrne T, Fargo JD, Montgomery AE, Roberts CB, Culhane DP, Kane V (2015) Screening for homelessness in the Veterans Health Administration: monitoring housing stability through repeat screening. Public Health Rep 130(6):684-692

18. Khan SS, Ning H, Wilkins JT, Allen N, Carnethon M, Berry JD, Sweis RN, Lloyd-Jones DM (2018) Association of body mass index with lifetime risk of cardiovascular disease and compression of morbidity. JAMA Cardiol 3(4):280-287

Publisher's note Springer Nature remains neutral with regard to jurisdictional claims in published maps and institutional affiliations. 